\title{
The prevalence and correlates of depression among patients with breast cancer, attending outpatient clinics at two cancer units in Sri Lanka
}

TAS Prabhath, R Ruben

\section{Abstract \\ Background}

Breast cancer is an invasive type of malignancy prevalent among females worldwide. Global figures indicate that depression occurs in $32.2 \%$ females with breast cancer. The prevalence and correlates of depression among patients with breast cancer in Sri Lanka are largely unknown. A better understanding of these data is essential to identify the burden of the disease and to plan appropriate interventions.

\section{Aims}

The aims of the study were to describe the prevalence of depression among patients with breast cancer in Sri Lanka and to identify associated socio-demographic and clinical factors.

\section{Methods}

This was a descriptive cross-sectional study conducted in two cancer units. Participants included females with pathologically proven breast cancer attending oncology clinics, and the sample size was 335. Participants were screened for depression using the Center for Epidemiologic Studies Depression
Scale (CES-D). Socio-demographic and clinical information regarding the cancer was collected using a questionnaire.

\section{Results}

The prevalence of clinical depression in the sample was $24.5 \%$. There was a significant association between the occurrence of depression and the participant age, partner's employment status, menopausal state, having dependent children, degree of social support, metastatic stage of cancer, past target therapy, and current hormonal therapy. Logistic regression analysis indicated a significant association between the degree of social support received and the presence of depression.

\section{Conclusions}

Almost a quarter of patients with breast cancer in this study were depressed. Patients' perception of the degree of social support appears to be a very significant predictor of depression in this group.

Key words: breast cancer, depression, Sri Lanka

SL J Psychiatry 2020; 11(2): 13-19

\section{Introduction}

Breast cancer is the most common invasive malignancy among females worldwide (1). According to the Cancer control programme of Sri Lanka, in 2014, breast cancer accounted for $25.2 \%$ of all types of cancers affecting females in Sri Lanka(2). Studies have shown the prevalence of depression in breast cancer to be very high compared to general population figures, although it varies widely across different settings, ranging from $1 \%$ to $56 \%$ $(3,4)$. Depression is reported to worsen the progression of cancer in many ways; and ultimately, the outcome of the cancer treatment becomes poorer if the patient is depressed (5). Therefore, patients with breast cancer should be screened for depression and offered appropriate treatment if they are found to be depressed.
The prevalence and correlates of depression among patients with breast cancer in Sri Lanka are poorly understood due to the scarcity of research in this area. These data are essential to identify the burden of the disease and also to plan appropriate interventions. This study aimed to determine the prevalence and sociodemographic and clinical correlates of depression among female patients with breast cancer attending out-patient clinics at two cancer units in Sri Lanka.

\section{Methods}

The study was conducted at the National Cancer Institute of Sri Lanka and Teaching Hospital Karapitiya. Ethical approval for the study was granted from the 
Ethics Review Committee at the Postgraduate Institute of Medicine, University of Colombo, Sri Lanka. Female patients with histopathological evidence of breast cancer, attending outpatient oncology clinics at those two centers, between the $1^{\text {st }}$ July-10 $0^{\text {th }}$ August, 2020 were considered eligible for the study. Participants were recruited from the outpatient clinics only, to avoid any bias related to an acute setting. After receiving information about the project, women who gave written consent were included in the study. Male patients and those with intellectual disabilities or significant acute medical problems were excluded from the study.

The total sample size was 335, and this was calculated based on a global depression prevalence of $32.2 \%$. The locally validated Sinhala version of the Centre for Epidemiological Studies for Depression Scale (CES D) was used to screen for depression, and a questionnaire designed by the authors for this study was administered to obtain socio-demographic and clinical (cancer-related and treatment-related) information (6).

The Statistical Package for Social Sciences (SPSS) was used to analyze the data. The analysis included descriptive statistics, and the Chi-square test was used to analyze for any associations between variables of interest, such as socio-demographic, cancer-related, and treatment-related factors and the occurrence of depression. A significance level of $\geq 0.5$ was applied in the analysis. Logistic regression was used for further analysis of categorical data found to be significantly associated with the occurrence of depression according to the results of the chi-square tests.

\section{Results}

Of the 335 participants, a total of 84 (24.5\%) were found to be suffering from either mild, moderate or severe depression. The distribution of the CES D score is given in Figure 1. Five socio-demographic factors were found to have a statistically significant association with the occurrence of depression, namely: Age $\left(\chi^{2}=5.016, \mathrm{df}=1\right.$, $\mathrm{p}=0.025)$, partner employment status $\left(\chi^{2}=3.905\right.$, $\mathrm{df}=1$, $\mathrm{p}=0.048)$, menopausal status $\left(\chi^{2}=5.221, \mathrm{df}=1, \mathrm{p}=0.022\right)$, number of children under patient's care $\left(\chi^{2}=5.134, \mathrm{df}=1\right.$, $\mathrm{p}=0.023)$, and degree of social support $\chi^{2}=17.866, \mathrm{df}=3$, $\mathrm{p}<0.001$ ) (Table 1). The prevalence of depression was greater in those who were younger compared to older participants. Depression was less in the group with currently employed partners, compared to others with partners with no current employment. Premenopausal women had a higher prevalence of depression. When the number of children under the patients' care was concerned, a lesser prevalence was found in the patient group with no children to care for, compared to the group who had children needing care. Participants reporting good and very good social support (as per the definitions in the questionnaire) had a lower rate of depression in contrast to the group with adequate or poor support.

Among cancer-related factors, those with metastatic cancer had significantly higher rates of depression $\left(\chi^{2}=3.871, \mathrm{df}=1, \mathrm{p}=0.049\right)$ compared to those with no metastasis. When treatment-related factors were concerned, the group treated with targeted therapy had a higher prevalence of depression $\left(\chi^{2}=5.148, \mathrm{df}=1\right.$, $\mathrm{p}=0.023)$. Those currently receiving hormonal therapy

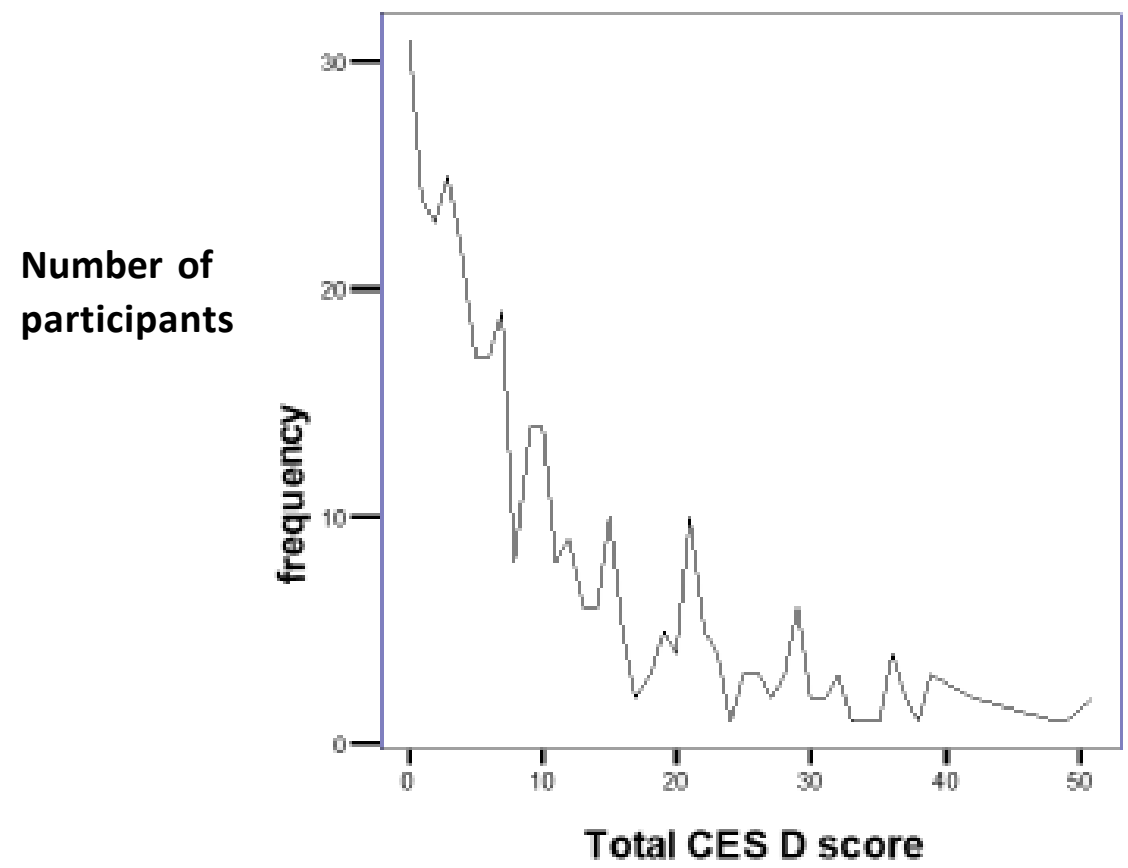

Dot/Lines show counts

Figure 1. Frequency distribution (in numbers) of total CES D score in the sample ( $n=335$ ); the cut-off level for clinical depression was a score of $\geq 16$. 
had a lesser prevalence of depression $\left(\chi^{2}=4.767, \mathrm{df}=1\right.$, $\mathrm{p}=0.029)$ compared to the non-hormonal therapy group. Logistic regression indicated that only social support was significantly associated with the risk of depression, with participants who reported good and very good social support having a significantly lower rate of depression (Table 2).

There was no significant association detected between marital status, educational level, employment status, family income, family group, presence of a history of medical condition or psychiatric illness, having a family history of psychiatric illness, degree of partner's support, local lymph node invasion stage of cancer, having a family history of breast cancer, duration since diagnosis, having a history of surgery, chemotherapy radiotherapy or hormonal therapy, or current chemotherapy, and the occurrence of depression.

Table 1. Associations between variables of interest and the presence of depression in women with breast cancer (based on chi square analysis, $n=335$ )

\begin{tabular}{|c|c|c|c|}
\hline Variable & $\chi^{2}$ & $d f$ & $P$ value \\
\hline \multicolumn{4}{|c|}{ Associations with socio-demographic factors and past medical history } \\
\hline Age & 5.016 & 1 & $0.025^{*}$ \\
\hline Partner employment status & 3.905 & 1 & $0.048^{*}$ \\
\hline Number of children under patient's care & 5.134 & 1 & 0.023* \\
\hline Marital status & 0.178 & 1 & 0.673 \\
\hline Educational level & 0.581 & 1 & 0.446 \\
\hline Employment status & 0.074 & 1 & 0.786 \\
\hline Family income & 0.743 & 2 & 0.690 \\
\hline Past psychiatric history & 1.995 & 1 & 0.158 \\
\hline Past medical history & 2.385 & 1 & 0.123 \\
\hline Family history of psychiatric illness & 0.100 & 1 & 0.752 \\
\hline \multicolumn{4}{|l|}{ Social support } \\
\hline Degree of social support & 17.866 & 3 & $0.000^{*}$ \\
\hline Degree of partner support & 0.751 & 1 & 0.386 \\
\hline \multicolumn{4}{|l|}{ Associations with cancer-related factors } \\
\hline Metastatic stage of cancer & 3.871 & 1 & $0.049 *$ \\
\hline Lymph node invasion & 0.037 & 1 & 0.847 \\
\hline Duration since diagnosis & 8.642 & 5 & 0.124 \\
\hline Family history of breast cancer & 2.515 & 1 & 0.113 \\
\hline \multicolumn{4}{|l|}{ Associations with treatment-related factors } \\
\hline Past targeted therapy & 5.148 & 1 & $0.023^{*}$ \\
\hline Current hormonal therapy & 4.767 & 1 & $0.029 *$ \\
\hline Past surgery & 0.170 & 1 & 0.680 \\
\hline Past chemo-therapy & 0.130 & 1 & 0.719 \\
\hline Past radio-therapy & 0.485 & 1 & 0.486 \\
\hline Past hormonal therapy & 0.725 & 1 & 0.395 \\
\hline Current chemo-therapy & 2.922 & 1 & 0.087 \\
\hline
\end{tabular}

$\chi^{2}=$ chi-square value $; \mathrm{df}=$ degree of freedom; $\mathrm{p}=$ level of significance; ${ }^{*}$ Significant associations 


\begin{tabular}{|c|c|c|c|c|c|}
\hline \multirow{2}{*}{$\begin{array}{l}\text { Character } \\
\text { Groups (variable) }\end{array}$} & \multirow[t]{2}{*}{ Coefficient } & \multirow{2}{*}{$\begin{array}{c}\text { Level of } \\
\text { significance } \\
\text { p value }\end{array}$} & \multirow[t]{2}{*}{ Odds ratio } & \multicolumn{2}{|c|}{ 95.0\% C.I. for odd ratio } \\
\hline & & & & Lower & Upper \\
\hline Age & -.024 & 0.397 & .977 & .925 & 1.031 \\
\hline Partner employment & .459 & 0.247 & 1.583 & .728 & 3.441 \\
\hline Menopausal status & -.246 & 0.629 & .782 & .289 & 2.118 \\
\hline Having children & -.011 & 0.978 & .989 & .461 & 2.124 \\
\hline Degree of support & .957 & 0.002 & 2.604 & 1.401 & 4.840 \\
\hline Metastatic stage & .489 & 0.269 & 1.630 & .685 & 3.879 \\
\hline Targeted therapy & .766 & 0.245 & 2.151 & .592 & 7.815 \\
\hline
\end{tabular}

C.I. = confidence interval.

\section{Discussion}

\section{The prevalence of depression}

Of the participants in this study, $24.5 \%$ screened positive for clinical depression, which was lower than the global reported rate of $32.2 \%$ (7). However, variations in rates of depression in those with breast cancer has been noted in other studies, and lower prevalence rates have been previously reported in some Asian countries (7). A large population-based cohort study done in China reported a depression prevalence of $26 \%$, and another study from Thailand found $16.7 \%$ participants with breast cancer to be depressed $(8,9)$. A study from India has reported a clinical depression point prevalence of $21.5 \%$ (10). These findings suggest that the rates for depression in women with breast cancer in Sri Lankan and other Asian countries maybe lower than rates reported in the West, but the reasons for this are not clear. Factors such as family support may play a role, and this is an area requiring further research.

\section{Associations with socio-demographic factors}

Similar to the results obtained from the current study, younger age has been associated with increased risk of depression in women with breast cancer, in several other studies (11-13). Difficulty accepting the cancer at a younger age, and anger against the diagnosis, has been suggested as possible explanations for this (14).

When partner employment is considered, the male partner's unemployment status is important as an indicator of family income, for many families in Sri Lanka. Although we could find no previous research evidence to confirm this in Sri Lanka, during our interviews with the patients in this study, it was evident that patients with breast cancer were worried about their partner's unemployment status, and therefore this may have contributed to the association between the partner's unemployment status and the occurrence of depression. Previous work has shown that premenopausal women were more likely to experience depression and other side effects related to various modes of treatment for breast cancer, and a similar increased rate of depression was seen in this group of patients in our study (15). However, there is also research showing the opposite association (16). Having young children needing care has been described as a vulnerability factor for depression in the general population, and this may play a role with regards to depression even in patients with breast cancer, as shown in our study. However, in contrast to previous work there was no association between the number of children and the occurrence of depression in our study (17).

Lack of social support was a very important risk factor for depression that emerged from our study -- and this has been previously reported in several other studies done in many different cultures $(9,14,18,19)$.

In contrast to international evidence, in our study there was no significant association between marital status, educational level, unemployment status, partner support and the occurrence of depression (18, 20, 21). Study limitations such as insufficient sample size to detect these individual associations or sampling errors due to the non-random sampling may have contributed to these differences. Having a comorbid medical condition and having a positive family history are risk factors for depression in the general population, but these risks seem to be non-significant in patients with breast cancer (10). 


\section{Association with cancer-related factors}

Metastatic breast cancer has a poor prognosis and its 5-year survival rate can be as low as $26 \%$, compared to non-metastatic breast cancer, which has a 5-year survival rate of almost $99 \%$ (22). Patients with distant metastasis have a higher symptom burden and stress due to chronic inflammatory reactions, which in turn makes them more vulnerable to become depressed $(23,24)$. All these multiple factors are likely to contribute to the higher rate of depression in those with metastatic breast cancer, as was seen in this study.

Local lymph node invasion itself did not show an increased risk of depression in this study. However there are various levels of invasion that were not considered in this study due to the unavailability of uniform pathological reports with the patients (16). If proper staging was considered there may have been significant associations with the prevalence of depression (25). Our study did not detect any significant association with family history of breast cancer and the occurrence of depression, and international evidence on this is variable (26). The duration since diagnosis has been shown to affect rates of depression in previous studies, but this was not seen in this study $(8,18)$.

\section{Association with treatment-related factors}

There is conflicting evidence concerning various modes of treatment modalities used in breast cancer and their association with depression $(17,27)$. Some studies have not detected any association with chemotherapy, hormonal therapy, radiotherapy, or surgery, while others showed significant associations with chemotherapy and surgery (17, 27-29). This current study also confirmed the heterogeneity of findings, given the positive association between depression risk and past target therapy, negative association with current hormone therapy treatment modalities, and no significant association with other treatment options. The reasons behind these differences in associations are not clear. However, depressive mood is a known side effect with chemotherapy, radiotherapy, and hormonal therapy, and psychological effects secondary to changes in bodily appearance after mastectomy have been attributed to depression in women who have undergone mastectomy (29).

\section{Limitations}

The study included a convenient sample taken from two major cancer units and was not a random sample representative of the country. Therefore, the generalizability of the results maybe limited. The sample size was calculated to detect the prevalence of depression but not to detect individual correlates. This inadequacy of sample size may be a reason why there was no significant association between certain socio-demographic, cancerrelated, and treatment-related factors and the occurrence of depression, as described above.
We were also not able to obtain the exact TNM classification with regards to each participant's breast cancer, due to the unavailability of uniform pathological reports or records. This is a limitation and may have contributed the fact that the there was no demonstrable association between the different stages of cancer and depression.

\section{Conclusions}

To the best of our knowledge, this is the first study to explore for prevalence and associations of depression in women with breast cancer in Sri Lanka. The findings of this study indicate that almost one quarter of the patients with breast cancer at the study sites were suffering from depression.

There was a significant association between the patient's age, partner's employment state, menopausal state, having children needing care, degree of social support, metastatic stage of cancer, past target therapy, and current hormonal therapy. Among these, the degree of social support emerged as an important factor associated with the occurrence of depression, based on logistic regression.

\section{Recommendations}

It is recommended that a proper screening method for depression be included in the routine breast cancer treatment package and patients who screen positive should be offered further psychiatric assessment and treatment if indicated.

Lack of social support being the most significant, as well as preventable association with the presence of depression, it is recommended that patients and caregivers, as well as medical practitioners be educated about this and measures be taken to improve social support for these patients.

\section{Acknowledgements}

The authors gratefully acknowledge the support rendered by the Directors, medical and other staff members, and participants (patients) of oncology units at National Cancer Institute Maharagama and Cancer unit at Teaching Hospital Karapitiya, Galle.

\section{Author contributions}

TASP carried out the research work, analyzed the data and prepared the manuscript. RR provided intellectual input, supervision and contributed to revisions of the article. Both authors have seen and approved the final version of the article.

\section{Conflicts of interest}

None declared. 
TAS Prabhath, Base Hospital, Kamburupitiya, Sri Lanka

R Ruben, Teaching Hospital, Karapitiya, Galle, Sri Lanka

Corresponding author: TAS Prabhath

Email: tasprabath@gmail.com

http://orcid.org/0000-0001-9474-4163

\section{References}

1. Street W. Breast Cancer Facts \& Figures 2019-2020. Atlanta: American Cancer Society, Inc. 2019. Available from https://www.cancer.org/content/dam/cancer-org/ research/cancer-facts-and-statistics/breast-cancer-factsand-figures/breast-cancer-facts-and-figures-2019-2020.

2. Cancer Incidence Data Sri Lanka 2014. National Cancer Control Program. Available from https://www.nccp. health.gov.lk/storage/post/pdfs/Cancer_ Incidence_in_Sri_Lanka_2014.pdf

3. Watson M, Haviland JS, Greer S, Davidson J, Bliss JM. Influence of psychological response on survival in breast cancer: a population-based cohort study. Lancet 1999; 354(9187): 1331-6.

4. Begovic-Juhant A, Chmielewski A, Iwuagwu S, Chapman L. Impact of Body Image on Depression and Quality of Life Among Women with Breast Cancer. J Psychosoc Oncol. 2012; 30: 446-60.

5. Sherrill C, Smith M, Mascoe C, Bigus E, Abbitt D. Effect of Treating Depressive Disorders on Mortality of Cancer Patients. Cureus [Internet]. 2017; [cited 2020 Oct 24];9(10). Available from: https://www.cureus.com/ articles/8003-effect-of-treating-depressive-disorders-onmortality-of-cancer-patients

6. Silva V de, Ekanayake S, Hanwella R. Validity of the Sinhala version of the Centre for Epidemiological Studies Depression Scale (CES-D) in out-patients. Ceylon Med J. 2014; 59(1): 8-12.

7. Pilevarzadeh $\mathrm{M}$, Amirshahi $\mathrm{M}$, Afsargharehbagh R, Rafiemanesh H, Hashemi S-M, Balouchi A. Global prevalence of depression among breast cancer patients: a systematic review and meta-analysis. Breast Cancer Res Treat. 2019; 176(3): 519-33.

8. Chen X, Lu W, Zheng Y, Gu K, Chen Z, Zheng W, et al. Exercise, tea consumption, and depression among breast cancer survivors. J Clin Oncol Off J Am Soc Clin Oncol. 2010; 28(6): 991-8.

9. Lueboonthavatchai P. Prevalence and psychosocial factors of anxiety and depression in breast cancer patients. J Med Assoc Thail Chotmaihet Thangphaet. 2007; 90(10): 2164-74.
10. Purkayastha D, Venkateswaran C, Nayar K, Unnikrishnan U. Prevalence of Depression in Breast Cancer Patients and its Association with their Quality of Life: A Crosssectional Observational Study. Indian J Palliat Care 2017; 23(3): 268-73.

11. Boing L, Pereira GS, de Araújo C da CR, Sperandio FF, Loch M da SG, Bergmann A, et al. Factors associated with depression symptoms in women after breast cancer. Rev Saúde Pública [Internet]. 2019 [cited 2020 Sep 18]; 53. Available from: https://www.ncbi.nlm.nih.gov/pmc/ articles/PMC6474749/

12. Mehnert A, Koch U. Psychological comorbidity and healthrelated quality of life and its association with awareness, utilization, and need for psychosocial support in a cancer register-based sample of long-term breast cancer survivors. J Psychosom Res. 2008; 64(4): 383-91.

13. Broeckel JA, Jacobsen PB, Balducci L, Horton J, Lyman GH. Quality of life after adjuvant chemotherapy for breast cancer. Breast Cancer Res Treat. 2000; 62(2): 141-50.

14. Mehnert A, Koch U. Psychological comorbidity and healthrelated quality of life and its association with awareness, utilization, and need for psychosocial support in a cancer register-based sample of long-term breast cancer survivors. J Psychosom Res. 2008; 64(4): 383-91.

15. Befort CA, Klemp J. Sequelae of Breast Cancer and the Influence of Menopausal Status at Diagnosis Among Rural Breast Cancer Survivors. J Womens Health. 2011; 20(9): 1307-13.

16. Rady A, Elkholy O, Abouelwafa H, Elsheshai A, Elnoium S, Mohammed A. Demographic and Clinical Correlates of Breast Cancer Patients with Depression. Neuropsychiatry 2018; 8(5): 1447-51.

17. Deshields T, Tibbs T, Fan M-Y, Taylor M. Differences in patterns of depression after treatment for breast cancer. Psychooncology. 2006; 15(5): 398-406.

18. Bener A, Alsulaiman R, Doodson L, Agathangelou T. Depression, Hopelessness and Social Support among Breast Cancer Patients: in Highly Endogamous Population. Asian Pac J Cancer Prev APJCP. 2017;18(7):1889-96.

19. Brinker J, Cheruvu VK. Social and emotional support as a protective factor against current depression among individuals with adverse childhood experiences. Prev Med Rep. 2017; 5: 127-33.

20. Tsaras K, Papathanasiou IV, Mitsi D, Veneti A, Kelesi M, Zyga S, et al. Assessment of Depression and Anxiety in Breast Cancer Patients: Prevalence and Associated Factors. Asian Pac J Cancer Prev APJCP. 2018; 19(6): 1661-9.

21. Ell K, Sanchez K, Vourlekis B, Lee P-J, Dwight-Johnson M, Lagomasino I, et al. Depression, correlates of depression, and receipt of depression care among lowincome women with breast or gynecologic cancer. J Clin Oncol Off J Am Soc Clin Oncol. 2005; 23(13): 3052-60.

22. Peart O. Metastatic Breast Cancer. Radiol Technol. 2017; 88(5): 519M-539M. 
23. Park EM, Gelber S, Rosenberg SM, Seah DSE, Schapira L, Come SE, et al. Anxiety and Depression in Young Women With Metastatic Breast Cancer: A Cross-Sectional Study. Psychosomatics. 2018; 59(3): 251-8.

24. Sotelo J, Musselman D, Nemeroff C. The biology of depression in cancer and the relationship between depression and cancer progression. Int Rev Psychiatry Abingdon Engl. 2014; 26: 16-30.

25. Breast Cancer Staging: TNM Classification for Breast Cancer. 2019 [cited 2020 Oct 10]; Available from: https:/ /emedicine.medscape.com/article/2007112-overview

26. Carvalho SMF de, Bezerra IMP, Freitas TH, Rodrigues RC da S, Carvalho IOC de, Brasil AQ, et al. Prevalence of major depression in patients with breast cancer. J Hum Growth Dev. 2015; 25(1): 68-74.

27. Torres MA, Pace TW, Liu T, Felger JC, Mister D, Doho $\mathrm{GH}$, et al. predictors of depression in breast cancer patients treated with radiation: role of prior chemotherapy and nuclear factor kappa B. Cancer. 2013; 119(11): 1951-9.

28. Cvetkovic J, Nenadovic M. Depression in breast cancer patients. Psychiatry Res. 2016; 240: 343-7.

29. Kim M-S, Kim SY, Kim J-H, Park B, Choi HG. Depression in breast cancer patients who have undergone mastectomy: A national cohort study. PloS One. 2017; 12(4): e0175395 